\title{
23. PRELIMINARY STUDIES OF MANGANESE-RICH CARBONATE NODULES FROM LEG 68, SITE 503, EASTERN EQUATORIAL PACIFIC ${ }^{1}$
}

\author{
Max Coleman, Isotope Geology Unit, Institute of Geological Sciences, London, United Kingdom \\ Andy Fleet, ${ }^{2}$ Department of Earth Sciences, Open University and Department of Geology, \\ Goldsmiths College, London, United Kingdom \\ and \\ Paul Donson, Isotope Geology Unit, Institute of Geological Sciences, London, United Kingdom
}

\begin{abstract}
Nodules occur in the siliceous calcareous ooze and siliceous marl at Site 503 in the eastern equatorial Pacific. They are present below a depth of about 11 meters throughout the green-colored reduced part of the section down to 228 meters, although they are most abundant between 30 and 85 meters. They are cylindrical or barrel-shaped, up to $70 \mathrm{~mm}$ long, and usually have an axial channel through them or are hollow. They appear to have formed around and/or within burrows. XRD studies and microprobe analyses show that they are homogeneous and consist of calcian rhododrosite and minor calcite; $\mathrm{Mn}$ is present to the extent of about $30 \%$. Isotopic analyses of the carbonate give carbon values which range from $-1.2 \%_{0}$ to $-3.8 \%$, and oxygen isotope compositions vary from $+4.0 \%_{0}$ to $+6.0 \%$. These values are different from those for marine-derived carbonates as exemplified by the soft sediment filling of a burrow: $\delta^{13} \mathrm{C},-0.26 \%$; $\delta^{18} \mathrm{O},+1.05 \%$. The carbon isotope data indicate that carbonate derived (possibly indirectly) from seawater was mixed with some produced by organic diagenesis to form the nodules. The $\delta^{18} \mathrm{O}$ values suggest that although they formed near the sediment surface, some modification or the introduction of additional diagenetic carbonate occurred during burial.
\end{abstract}

\section{OCCURRENCE AND MORPHOLOGY}

Nodules were found within the Neogene pelagic sediments cored at Site 503 in the eastern equatorial Pacific (see site chapter). They occur in situ from a depth of 13 meters (503B-4-1, $143 \mathrm{~cm}$ ) down to 228 meters (503A53-2. $12 \mathrm{~cm}$ ), though they are abundant only between depths of about 30 and 85 meters (Fig. 1). Some nodules also occur in the disturbed upper part of cores (see Introduction, this volume) at levels which must be considered their maximum depth of occurrence. They are all restricted to the "reducing" green-colored subunits $1 \mathrm{~B}$ and $1 \mathrm{C}$ of the sequence (Fig. 1).

The nodules are generally cylindrical (Fig. 2A, C, D), though some are barrel-shaped (Fig. 2B, E), and are about 50 to $70 \mathrm{~mm}$ long. In situ, the nodules were found with their long axes oriented vertically. They are hollow, usually having axial channels running through them. These channels occasionally contain pellets (e.g., Fig. 2A) that are similar to those in some of the open burrows which occur down to 64 meters at this site and are thought to be fecal in origin (cf. Fig. 6, site chapter, this volume). Because of these characteristics the nodules are believed to have formed within the sediment around burrows. This is borne out by two occurrences of hardening around burrows at 13 meters (503B-4-1, 143 $\mathrm{cm}$ and 503B-4-2, $36 \mathrm{~cm}$ ), which probably represent partially formed or incipient nodules. In some instances the axial channels contain unconsolidated sediment (e.g., Fig. 2C) but in others they have been washed clean dur-

\footnotetext{
${ }^{1}$ Prell, W. L., Gardner, J. V., et al., Init. Repts. DSDP, 68: Washington (U.S. Govt. Printing Office).

2 Present address: Exploration and Production Division, British Petroleum Research Centre, Sunbury-on-Thames, United Kingdom.
}

ing sawing in half for curation (e.g., Fig. 2D). Occasionally the structure of the axial channel is complex (e.g., Fig. 2E), perhaps because the original sediment infilling of the channel was itself burrowed and subsequently became partially lithified around the secondary burrows. The nodules are fine grained but often visibly zoned parallel to the axial channels, with darker zones around the channel and lighter ones towards the exterior (e.g., Fig. 2A). Also, small pores or channels, up to 1 $\mathrm{mm}$ in diameter, permeate the nodules. They may be voids created during the formation of the nodules, or they may be postformational borings.

We have been unable to find reports of similar nodules from the deep sea though morphologically similar nodules are known from shelf environments (e.g., flint nodules from the Cretaceous chalk of South EnglandFig. 2F). H. Cook (personal communication) recollects that similar nodules occur within the nannofossil oozes drilled on Leg 9, but we were unable to find any reference to these in Hays et al. (1972). In order to elucidate the nature and origin of the nodules we have undertaken various analyses, which are discussed below.

\section{MINERALOGICAL AND CHEMICAL ANALYSES}

\section{X-Ray Diffraction Analyses}

Samples from two nodules (503A-27-1, $23 \mathrm{~cm}$ and 503A-33-1, 108 $\mathrm{cm}$ ) were examined by X-ray diffraction (XRD) using powder photographs. Samples from both nodules and from the separate visible zones gave similar results. The main phase appears to be a calcian rhodochrosite with a d-spacing at $2.87 \AA$, compared to $2.84 \AA$ for rhodochrosite and $3.04 \AA$ for calcite. Although the diffraction data for kutnahorite show some differences from those for the nodule carbonate, this mineral cannot be eliminated absolutely and must be considered as a possible alternative identification. The lines on the film were rather diffuse, suggesting a poorly crystallized mineral. Minorto-trace amounts of better crystallized calcite was the only other phase identified in any of the samples. 


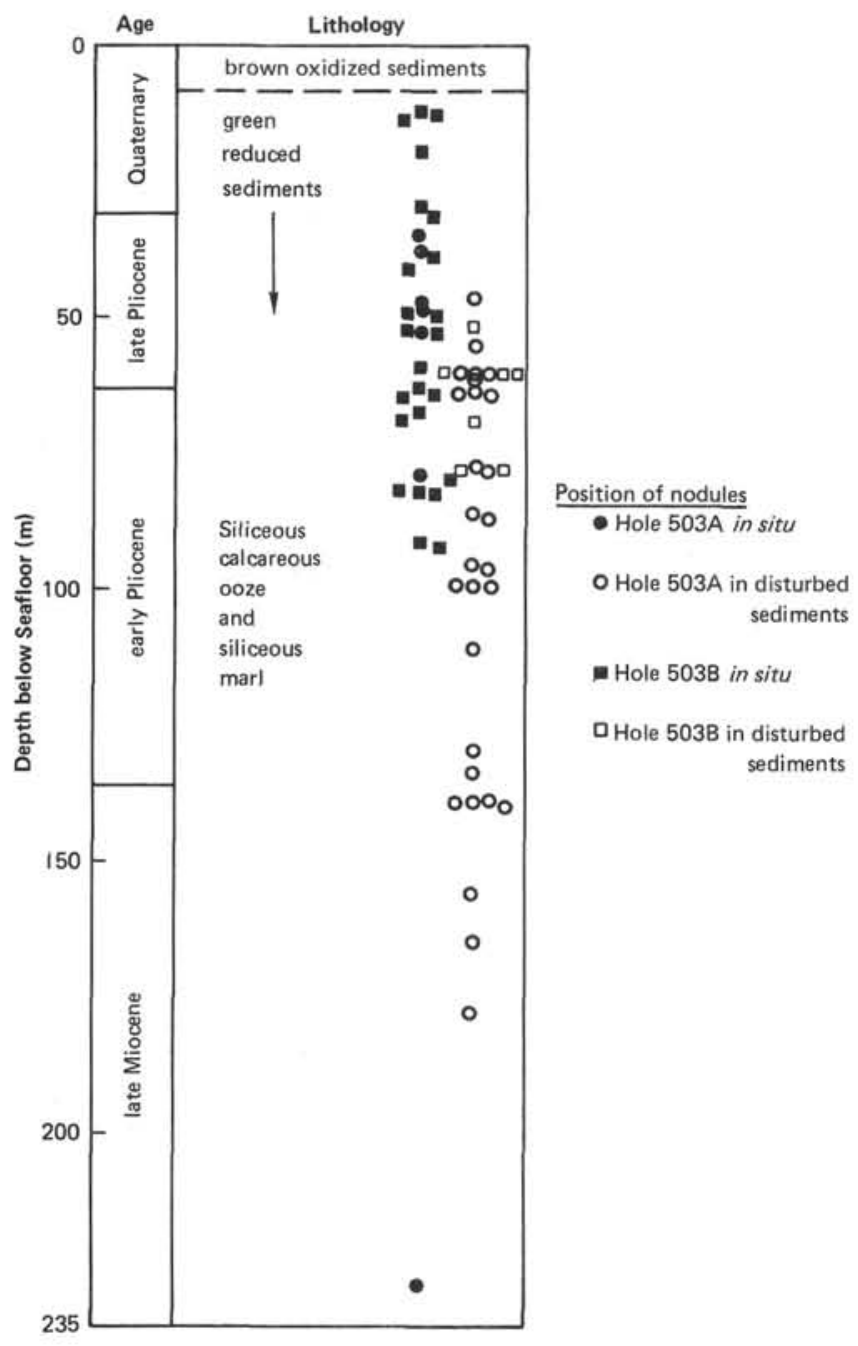

Figure 1. Stratigraphy and location of nodules at Site 503.

\section{Microprobe Analyses}

We carried out microprobe analyses in order to see whether or not the nodules are chemically homogeneous and, in particular, to find out whether the visible internal zones of the nodules differ in their chemical compositions.

The samples were first analyzed using an energy-dispersive electron microprobe: a Link Systems 860 with Kevex E.D. attached to a Cambridge Instruments Geoscan. An accelerating voltage of $15 \mathrm{kV}$, a specimen current on the cobalt metal internal standard of $0.5 \times 10^{-8}$ A, 100-s live-time counting time, and synthetic and pure mineral and pure metal standards were used. The samples were then analyzed using a wavelength-dispersive Cambridge Instrument Microscan 9 microprobe. An accelerating voltage of $20 \mathrm{kV}$, a specimen current on the Faraday cage of $2.50 \times 10^{-8} \mathrm{~A}$, a counting time of $10 \mathrm{~s}$, and pure and synthetic mineral and pure metal standards were used.

The results of these analyses are given in Table 1 . No other elements were detected in significant concentrations. In order to derive the totals, calcium, magnesium, and manganese were calculated as carbonates and all other elements as oxides. The presence of water is believed to account for the low totals.

No systematic variation was found across the macroscopic zones within the nodules. Also, the analyses, which are arranged in order of increasing silicon content in Table 1, show no clear interelement variability, although iron tends to increase and magnesium, and to some extent calcium, to decrease with increasing silicon content. The variation in composition must reflect the incorporation in the nodules of lithog- enous clays and biogenic silica and calcite, which, because of the finegrained nature of the material, could not be resolved by microprobe. We therefore, consider it unrealistic to calculate an exact compositional formula for the nodules from these data, although we do believe that the mean given in Table 1 indicates the relative proportions of the constituents of the nodule carbonate.

As well as analyzing the microcrystalline "matrix" of the nodules, we also carried out partial analyses of patches of clear crystalline material, which were not recognizable as fragments of microfossils and gave variable $\mathrm{Ca}: \mathrm{Mn}$ ratios. Some of these grains contain little manganese, whereas others have atomic ratios for calcium and manganese of about 1:1. For example, one crystal (calculated as carbonate) gave the analysis $\mathrm{MnCO}_{3}, 48.6 \% ; \mathrm{MgCO}_{3}, 3.68 \% ; \mathrm{CaCO}_{3}, 48.2 \%$, totaling $100.5 \%$ and having the formula $\mathrm{Ca}\left(\mathrm{Mn}_{0.9} \mathrm{Mg}_{0.1}\right)\left(\mathrm{CO}_{3}\right)_{2}$. Because these clear crystalline patches in the nodules appear to be calcite or carbonates intermediate in composition between the "matrix" of the nodules and calcite, they may represent biogenic calcite in the process of being altered to the rhodochrosite which makes up the nodules. The analyses of the nodule "matrix" and the clear crystalline patches are consistent with the conclusion, based on X-ray diffraction studies, that the nodules consist mainly of calcian rhodochrosite with minor calcite.

Rare opaque grains are also present in the nodules. Microprobe analysis showed one of these to be pyrite. This, together with the minor amounts of sulphur detected in one nodule (Sample 503B-19-3, $18-20 \mathrm{~cm}$ ), supports the shipboard observation, when the nodules were first cut open, that blackening around the axial channel in a number of nodules probably indicates the presence of sulfides.

\section{Isotope Analyses}

Subsamples of up to $100 \mathrm{mg}$ were taken from sections of each nodule using a hand-held high-speed drill with a $1.5-\mathrm{mm}$ diameter, diamond-impregnated burr tip. Where possible, successive samples were taken from the outermost part of each nodule to the center: each subsample of a nodule was given a suffix from "a" to "e."

Residual organic matter can contaminate the carbon dioxide produced for analysis where interferences in the mass spectrum give characteristic problems of measurement and may lead to spurious results (Weber et al., 1976). Although the samples appeared visually to be pure, some were split into two aliquots, one of which was treated with a low temperature oxygen plasma (Nanotech, Plasmaprep) to oxidize any possible organic matter. As a check, samples of the laboratory calcite standard were treated similarly at the same time. Subsequent isotope analysis confirmed that the treatment had no effect on pure calcite and that the untreated nodule samples gave reliable results, implying a negligible organic content. Approximately $10 \mathrm{mg}$ of each sample were reacted with $100 \%$ phosphoric acid in vacuo at $25^{\circ} \mathrm{C}$, following a method essentially similar to that described by McCrea (1953). The resultant carbon dioxide was analyzed isotopically using a V.G. Isogas $903-\mathrm{S}$ triple collector mass spectrometer. The isotopic composition is expressed as parts per thousand $(\% 0)$ variation from the international PDB standard. The positive and negative values are referred to as heavy and light, respectively.

The isotopic analysis of carbonates by this, the usual, method produces gas which differs from the solid in its oxygen isotope composition by about $10 \%$. The difference varies with the mineralogy of the carbonate (Sharma and Clayton, 1965) and a simple correction can be used. For this purpose the samples were assumed to be pure calcite, and a correction for the proportion of $\mathrm{MnCO}_{3}$ was not applied. A sample of pure $\mathrm{MnCO}_{3}$ will thus have a $\delta^{18} \mathrm{O}$ value which is $0.13 \%$ too negative. In addition, the usual corrections for isobaric interferences and instrumental effects were applied to the raw data (Craig, 1957; Deines, 1970). The results are given in Table 2; both $\delta^{13} \mathrm{C}$ and $\delta^{18} \mathrm{O}$ are with respect to PDB. All the samples in Table 2 are nodular carbonates, with the one exception of Sample 503B-8-2, 70-72A, which is the sediment infill of a burrow (n.b. 503B-8-2, 70-72B is a nodular carbonate, therefore). Replicate analyses of the same powder generally gave results within a range of $0.02 \%$ for $\delta^{13} \mathrm{C}$ and $0.03 \%$ for $\delta^{18} \mathrm{O}$. The laboratory standard against which these samples were measured was originally calibrated with respect to SMOW and a range of carbonate standards. Nevertheless, since a new isotopic reference carbonate, NBS 19 , is being circulated at present, we note our preliminary determination of its composition: $\delta^{13} \mathrm{C}=+1.87 \%, \delta^{18} \mathrm{O}=-2.20 \%$. 


\section{DISCUSSION}

The occurrence of manganese-rich carbonate nodules of this type in this environment has not been reported before, to our knowledge, but the diagenetic behavior of manganese has been described in a number of publications very well summarized by Froelich et al. (1979). The movement of manganese in a sediment is controlled by oxidation of organic matter with concomitant reduction of $\mathrm{MnO}_{2}$ buried with the sediment; the resultant soluble $\mathrm{Mn}^{2+}$ diffuses up, driven by a concentration gradient produced by its fixation on oxidation to $\mathrm{MnO}_{2}$ at the base of the oxic zone. In this way manganese is stripped from the accumulating sediment and concentrated near its surface (Lynn and Bonatti, 1965). The presence of manganese-rich carbonate nodules indicates that their formation is interfering with the normal cycle by providing an alternative sink for $\mathrm{Mn}^{2+}$.

The presence of the manganese-rich carbonate nodules throughout the length of the core implies that they are formed over a considerable range of depths or, more probably, that they are produced near the sediment surface and survive burial with the sediment. The former possibility cannot be ignored, because if the reoxidation of manganese to $\mathrm{MnO}_{2}$ in the oxic zone is not complete then the pore waters would become saturated with $\mathrm{Mn}^{2+}$. This situation could arise from an increase in the rate of sedimentation or the advent of less-oxidizing conditions in the bottom waters. If this were the case, any of the successive zones of diagenesis of organic matter could produce carbonate which would be manganiferous. The fact that these concretionary carbonates have mineralogically similar burrow-fills suggests a high-level origin but does not preclude a subsequent infilling of void space. Equally, however, burrows do form microenvironments which can allow local less-oxic conditions to prevail: this effect can be seen in the early local precipitation of pyrite before a sediment has been buried to an extent sufficient for general sulfate reduction to occur (Coleman and Hudson, 1980). Stable isotope results should give additional evidence on the formation of these carbonates.

\section{Carbon Isotopes}

The diagenetic degradation of organic matter in mudstones, by successive processes during burial, produces carbonates with a mineralogy and isotope composition characteristic of each particular process (Curtis, 1977). However, from all those operating at higher level zones (early with respect to the time of sedimentation), the carbon of the neoformed carbonate is similar to that of the original organic matter. This isotope composition is noticeably greatly depleted in ${ }^{13} \mathrm{C}$ with respect to marine carbonate, which has a value near $0 \%$ with respect to PDB, which is itself a marine carbonate. Thus organogenetic carbonates are isotopically distinctive and may have values as negative as $-20 \%$ to $-30 \%$ (Hudson, 1977).

The carbonates from these nodules all have values in the range $-1.2 \%$ to $-3.8 \%$, noticeably lighter than the values for primary marine carbonate and not at all similar to those for organic-derived carbonate produced by sulfate reduction (about $-15 \%$ ), as reported by Coleman and Raiswell (1981). In the latter case dilution of pure organic-derived carbonate with marine carbonate has been shown probable. In the present study, it appears that the system is dominated by marine carbonate with only a small organogenetic component. The sediment filling of one nodule (Sample 503B-8-2, 70$72 \mathrm{~A}$ ) has a carbon value of $-0.26 \%$, more typical of marine carbonate.

The nodule sample with the heaviest carbon value is Sample 503A-53-2, 12-14 cm, which is also the deepest one. By plotting $\delta^{13} \mathrm{C}$ against depth (Figs. 3 and 4), a possible trend to heavier values with depth can be seen toward the bottom of Hole 503A; but the data from Hole 503B, which are shallower samples, show no trends.

There are two possible implications of the overall carbon isotope composition. It is possible that the nodules were formed near the sediment surface where downward diffusion of dissolved bicarbonate and upward migration of organogenetic bicarbonate allowed the latter's contribution to be diluted considerably. Alternatively, the carbonate may have been precipitated from pore waters in which dissolution of marine carbonate was the dominant source and which need not occur at such a high level. The depth of precipitation of the carbonate may be indicated by its oxygen isotope composition, as will be discussed.

\section{Oxygen Isotopes}

The oxygen isotope composition of a carbonate mineral depends on that of the water from which the mineral precipitated, but it is fractionated from that value by an amount which is a precise function of temperature. The calibration of isotopic fractionation as a function of temperature in the low-temperature range is not known for manganese carbonate. Nevertheless, changes in temperature will produce effects in the same sense for all carbonates (O'Neil et al., 1969); that is, at higher temperatures the carbonate has a more negative $\delta^{18} \mathrm{O}$ value. During burial, successive diagenetic carbonates will have progressively more negative $\delta^{18} \mathrm{O}$ with increase in temperature, but this effect is enhanced by alterations in the isotope composition of the pore water. As a result of diagenetic reactions the pore water may become up to $3 \%$ lighter (Lawrence et al., 1975). Although this may complicate the calculation of temperatures, the oxygen isotope composition of carbonates do give accurate information on their relative depths of formation.

Examination of Table 2 shows that the oxygen isotope values are very much heavier than those produced in a normal marine environment. If the samples were calcite this would imply impossible (subzero) temperatures. However, the fractionation of oxygen isotopes between manganese carbonate and water is greater than that of calcite at higher temperatures ( $\mathrm{O}$ 'Neil et al., 1969) and may apply at lower temperatures too. When the oxygen data for the two holes are plotted against depth (Figs. 5 and 6) it can be seen that there is a general trend to lighter values with depth for Hole 503A but not 


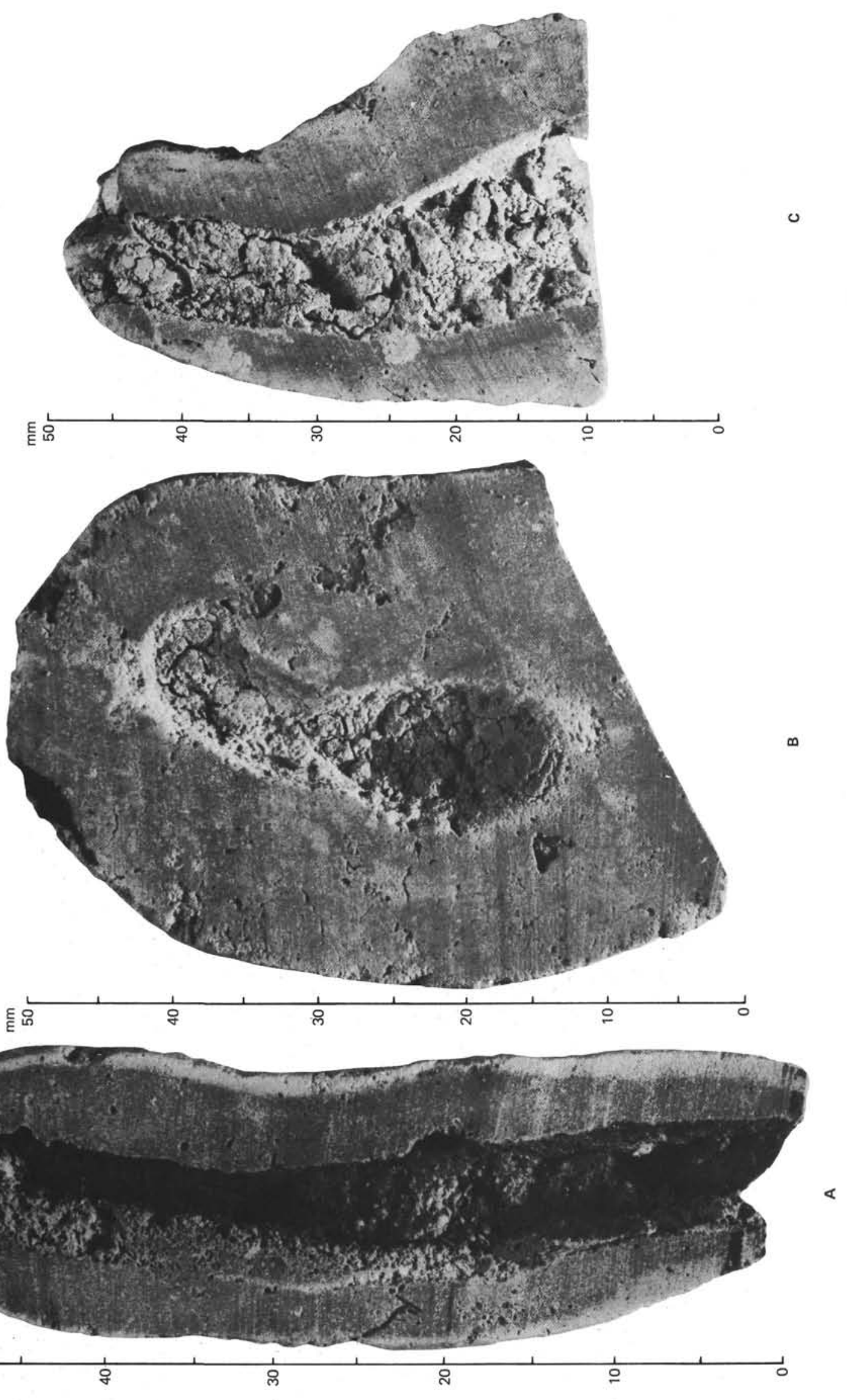




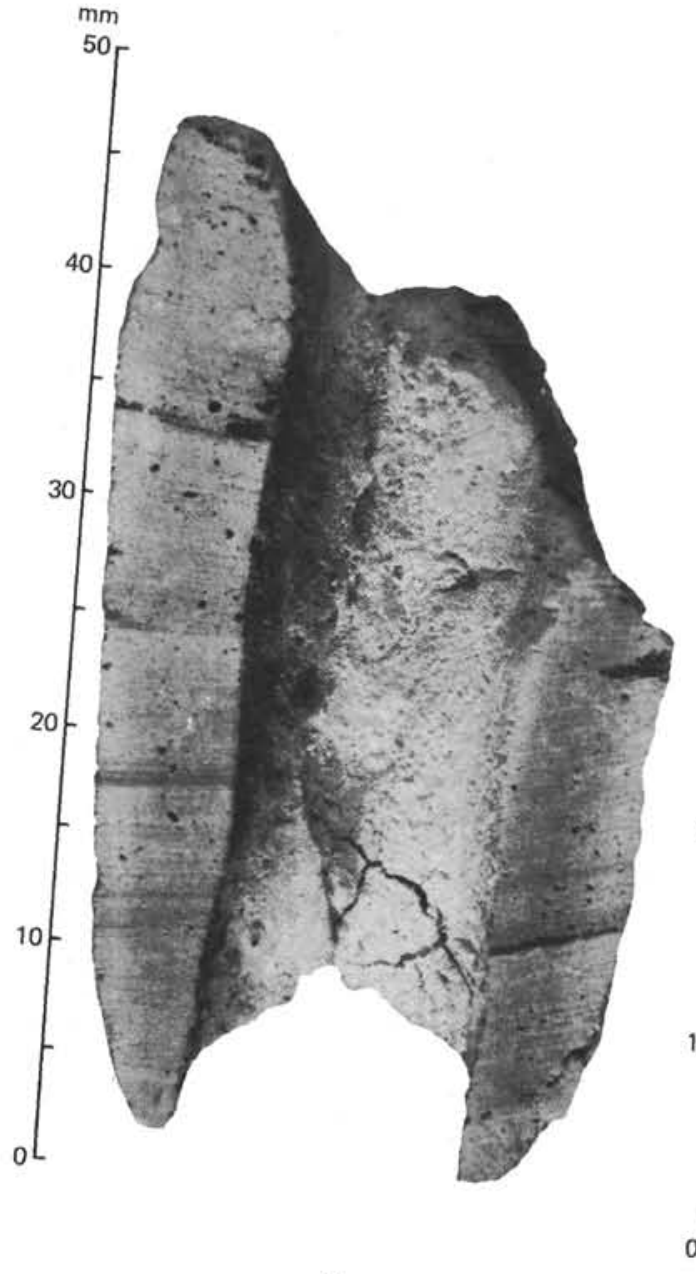

D

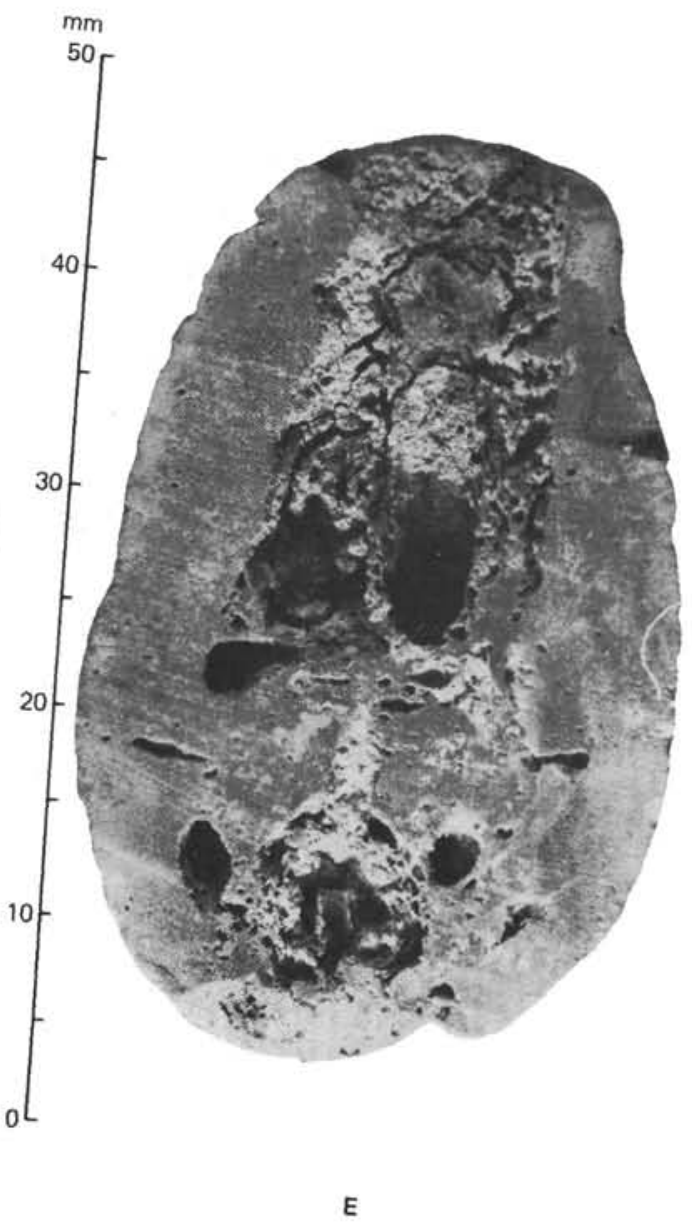

$\stackrel{+}{\sim}$

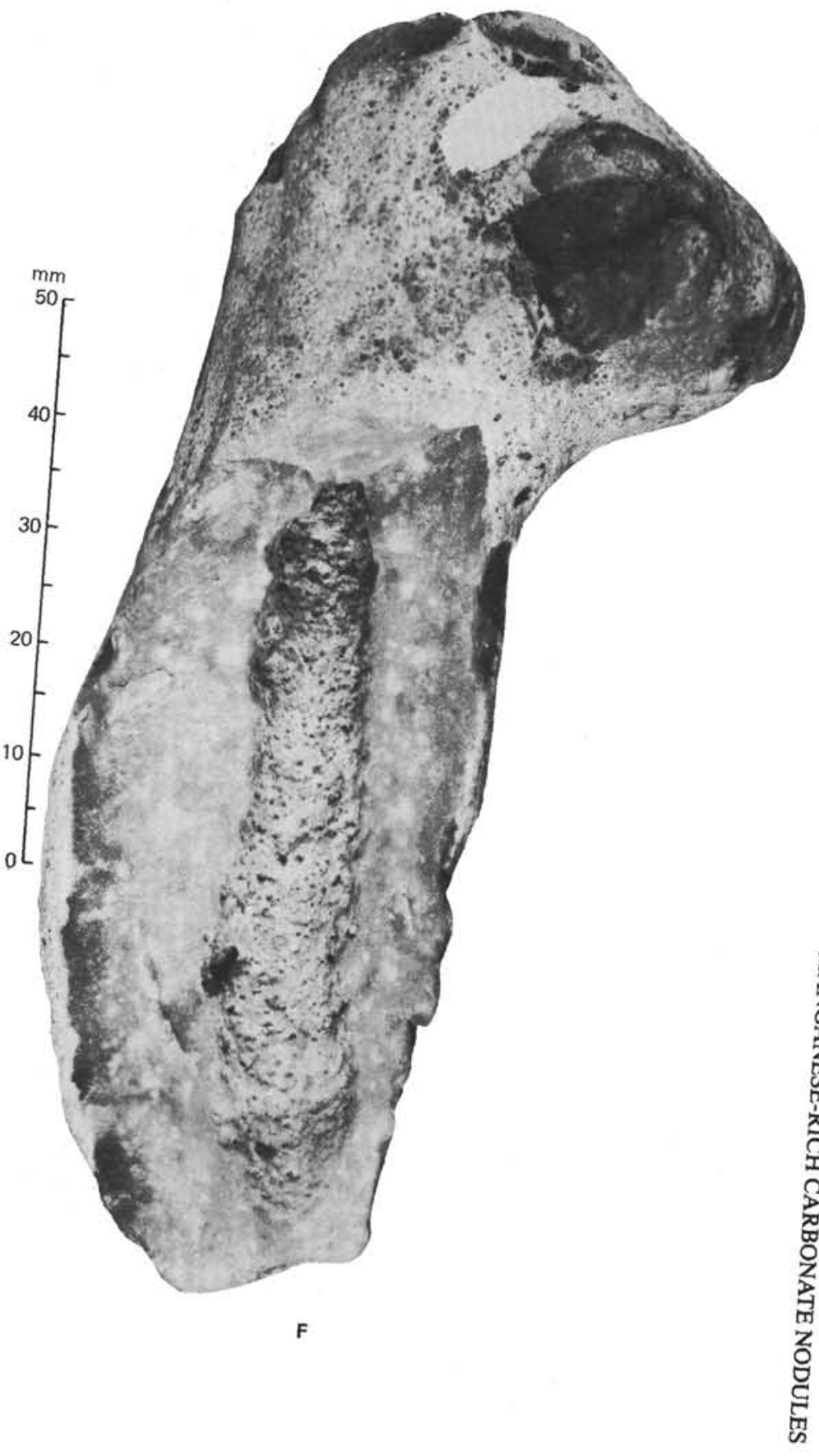


Table 1. Microprobe analyses (wt. \%).

\begin{tabular}{|c|c|c|c|c|c|c|c|c|c|c|c|c|}
\hline $\begin{array}{c}\text { Sample } \\
\text { (interval in } \mathrm{cm} \text { ) }\end{array}$ & $\mathrm{Ca}$ & $\mathrm{Fe}$ & $\mathrm{Mg}$ & $\mathrm{Si}$ & $\mathrm{Al}$ & $\mathrm{Mn}$ & $\mathrm{Na}$ & K & $\mathrm{P}$ & $\mathrm{S}$ & Total $^{\mathrm{a}}$ & Probe $^{b}$ \\
\hline $503 \mathrm{~A}-15-2,57-60$ & 9.08 & b.d & 1.66 & 0.45 & b.d & 30.1 & - & - & 0.11 & b.d & 92.6 & GS \\
\hline $503 \mathrm{~A}-15-2,57-60$ & 8.96 & 0.81 & 1.75 & 1.56 & 0.30 & 28.0 & - & - & b.d & b.d & 92.0 & GS \\
\hline $503 \mathrm{~A}-31-1,5-7$ & 13.4 & 0.30 & 1.58 & 0.08 & b.d & 28.3 & b.d & - & 0.09 & - & 98.9 & Mk 9 \\
\hline $503 \mathrm{~A}-31-1,5-7$ & 12.3 & 0.47 & 1.73 & 0.71 & 0.12 & 27.9 & b.d & - & 0.06 & - & 97.6 & Mk 9 \\
\hline $503 \mathrm{~A}-31-1,5-7$ & 13.0 & 0.53 & 1.99 & 1.67 & 0.33 & 30.2 & - & - & b.d & b.d & 107.4 & GS \\
\hline $503 \mathrm{~A}-31-1,5-7$ & 10.8 & 0.30 & 1.72 & 1.72 & 0.24 & 28.1 & b.d & - & 0.08 & - & 96.4 & Mk 9 \\
\hline 503B-13-1, 6-8 & 8.49 & 0.45 & 1.78 & b.d & b.d & 33.0 & - & - & 0.11 & b.d & 97.2 & Mk 9 \\
\hline $503 \mathrm{~B}-13-1,6-8$ & 8.17 & 0.43 & 1.72 & 0.06 & b.d & 32.3 & b.d & b.d & 0.10 & b.d & 94.9 & Mk 9 \\
\hline $503 \mathrm{~B}-13-1,6-8$ & 10.7 & 0.45 & 1.63 & 0.17 & b.d & 31.4 & - & - & 0.10 & b.d & 99.2 & Mk 9 \\
\hline $503 \mathrm{~B}-13-1,6-8$ & 9.61 & 0.37 & 1.65 & 0.25 & b.d & 31.4 & 0.08 & b.d & 0.09 & b.d & 96.7 & Mk 9 \\
\hline $503 \mathrm{~B}-13-1,6-8$ & 9.09 & 0.47 & 1.67 & 0.29 & 0.11 & 30.2 & b.d & - & 0.10 & - & 93.4 & Mk 9 \\
\hline $503 \mathrm{~B}-13-1,6-8$ & 10.4 & 0.54 & 1.59 & 0.48 & 0.13 & 30.5 & 0.12 & - & 0.10 & - & 97.7 & Mk 9 \\
\hline $503 \mathrm{~B}-13-1,6-8$ & 9.87 & 0.55 & 1.65 & 0.51 & 0.11 & 30.2 & - & - & 0.10 & b.d & 95.8 & Mk 9 \\
\hline 503B-13-1, 6-8 & 7.38 & 1.14 & 1.60 & 0.88 & 0.15 & 28.1 & - & - & 0.06 & 0.06 & 86.7 & Mk 9 \\
\hline 503B-13-1, 6-8 & 8.72 & 0.74 & 1.69 & 1.28 & 0.22 & 30.2 & - & - & 0.08 & b.d & 95.1 & Mk 9 \\
\hline $503 \mathrm{~B}-13-1,6-8$ & 8.44 & 0.71 & 1.54 & 2.05 & 0.76 & 28.3 & 0.30 & - & 0.07 & - & 92.9 & Mk 9 \\
\hline 503B-13-1, 6-8 & 9.79 & 0.70 & 1.64 & 2.20 & 0.22 & 29.5 & - & - & 0.13 & b.d & 98.2 & GS \\
\hline $503 \mathrm{~B}-13-1,6-8$ & 8.02 & 0.51 & 1.65 & 2.31 & 0.11 & 28.7 & - & - & 0.06 & b.d & 91.7 & Mk 9 \\
\hline 503B-13-1, 6-8 & 4.84 & 1.37 & 1.11 & 4.97 & 0.39 & 19.4 & 0.08 & - & 0.07 & - & 70.0 & Mk 9 \\
\hline 503B-16-2, 105-107 & 9.87 & b.d & 1.34 & 1.12 & 0.16 & 23.5 & - & - & - & - & 81.2 & GS \\
\hline $503 \mathrm{~B}-16-2,105-107$ & 10.1 & b.d & 1.40 & 1.13 & 0.18 & 23.7 & - & - & 0.11 & b.d & 82.7 & GS \\
\hline $503 \mathrm{~B}-16-2,105-107$ & 11.3 & b.d & 1.42 & 1.12 & b.d & 24.0 & - & - & 0.14 & b.d & 86.1 & GS \\
\hline $503 \mathrm{~B}-16-2,105-107$ & 8.86 & 0.35 & 1.52 & 0.97 & 0.15 & 24.2 & - & - & 0.10 & b.d & 81.0 & GS \\
\hline $503 \mathrm{~B}-19-3,18-20$ & 10.9 & 0.63 & 1.68 & 0.97 & 0.48 & 28.7 & - & - & 0.08 & b.d & 97.0 & Mk 9 \\
\hline $503 \mathrm{~B}-19-3,18-20$ & 10.6 & 0.83 & 1.82 & 1.01 & 0.30 & 28.6 & 0.10 & 0.09 & b.d & 0.26 & 97.1 & Mk 9 \\
\hline 503B-19-3, 18-20 & 9.66 & 1.01 & 1.62 & 1.32 & 0.23 & 28.3 & - & - & 0.08 & b.d & 93.7 & Mk 9 \\
\hline 503B- $19-3 ; 18-20$ & 9.73 & 0.48 & 1.64 & 2.92 & 0.12 & 29.0 & 0.08 & b.d & b.d & 0.29 & 98.5 & Mk 9 \\
\hline $503 \mathrm{~B}-19-3,18-20$ & 6.90 & 1.65 & 1.57 & 4.55 & 0.69 & 22.0 & 0.11 & 0.28 & b.d & 0.28 & 82.9 & Mk 9 \\
\hline Mean ${ }^{c}$ & 9.61 & $<0.61$ & 1.62 & $<1.36$ & $<0.26$ & 28.1 & $<0.12$ & $<0.19$ & $<0.12$ & $<0.22$ & & \\
\hline
\end{tabular}

Note: Analysts were J. C. Bevan and A. J. Fleet. b.d = below detection limit; $-=$ not determined.

a Total calculated as $\mathrm{CaCO}_{3}, \mathrm{FeO}^{*}, \mathrm{MgCO}_{3}, \mathrm{SiO}_{2}, \mathrm{Al}_{2} \mathrm{O}_{3}, \mathrm{MnCO}_{3}, \mathrm{Na}_{2} \mathrm{O}, \mathrm{K}_{2} \mathrm{O}, \mathrm{P}_{2} \mathrm{O}_{5}$, and $\mathrm{SO}_{2}$.

b Probes used: GS-Geoscan; MK 9-Microscan 9 microprobe.

c $<$ indicates that some analyses, not included in mean, gave results below the adopted detection limit.

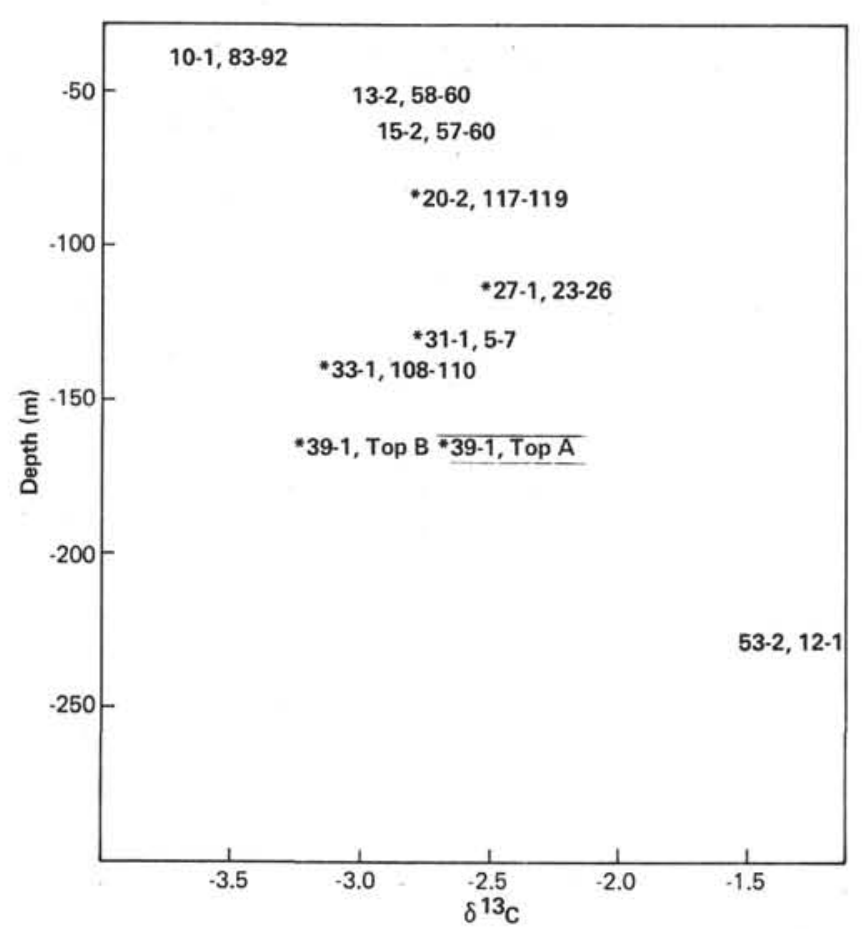

Figure 3. Variation of $\delta^{13} \mathrm{C}$ of carbonate with depth for Hole 503A. $(*=$ sample is not in situ: $)$

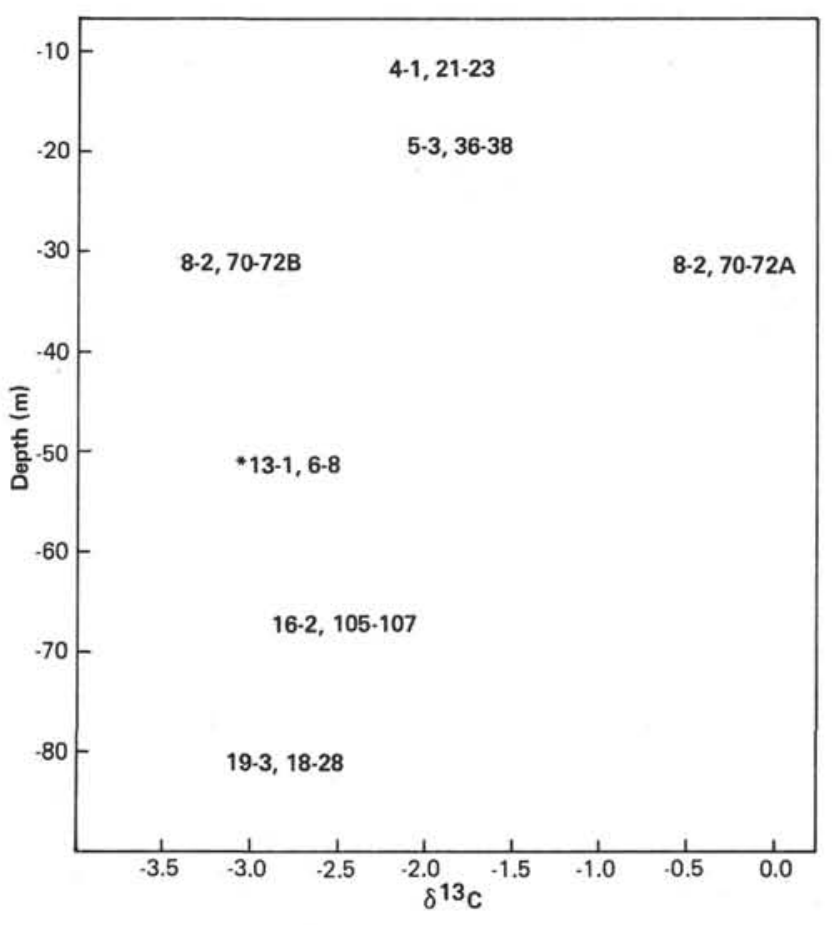

Figure 4. Variation of $\delta^{13} \mathrm{C}$ of carbonate with depth for Hole 503B. $(*=$ sample is not in situ .) 
Table 2. Isotope results.

\begin{tabular}{|c|c|c|c|c|c|c|c|c|}
\hline \multirow{2}{*}{$\begin{array}{l}\text { Depth } \\
\text { (m) }\end{array}$} & \multirow{2}{*}{$\begin{array}{c}\text { Sample } \\
\text { (interval in } \mathrm{cm} \text { ) }\end{array}$} & \multirow[b]{2}{*}{ Subsample } & \multirow[b]{2}{*}{${ }^{13} \mathrm{C}$} & \multirow[b]{2}{*}{${ }_{8}^{18} \mathrm{O}$} & \multicolumn{4}{|c|}{ Average values } \\
\hline & & & & & ${ }_{b^{13} \mathrm{C}}$ & $\sigma$ & ${ }^{18} \mathrm{O}$ & $\sigma$ \\
\hline \multirow[t]{4}{*}{37.9} & 503A-10-1, 83-92 & $\mathbf{a}$ & -3.84 & +5.76 & -3.52 & 0.31 & +5.64 & 0.15 \\
\hline & & b & -3.63 & +5.71 & & & & \\
\hline & & c & -3.50 & +5.67 & & & & \\
\hline & & d & -3.10 & +5.43 & & & & \\
\hline \multirow[t]{2}{*}{52.2} & $503 A-13-2,58-60$ & a & -2.75 & +4.81 & -2.83 & 0.11 & +4.80 & 0.02 \\
\hline & & a & -2.90 & +4.78 & & & & \\
\hline 61.0 & $503 \mathrm{~A}-15-2,57-60$ & a & $\begin{array}{l}-2.68 \\
-2.74\end{array}$ & $\begin{array}{l}+5.77 \\
+5.53\end{array}$ & -2.71 & 0.04 & +5.56 & 0.17 \\
\hline \multirow{2}{*}{83.7} & -503A-20-2, 117-119 & a & -2.48 & $\begin{array}{l}+5.53 \\
+4.44\end{array}$ & -2.54 & 0.08 & +4.56 & 0.17 \\
\hline & & b & -2.59 & +4.68 & & & & 0.17 \\
\hline \multirow[t]{5}{*}{112.0} & -503A-27-1, 23-26 & a & -2.52 & +4.91 & -2.29 & 0.16 & +4.66 & 0.19 \\
\hline & & b & -2.36 & +4.72 & & & & \\
\hline & & c & -2.27 & +4.72 & & & & \\
\hline & & d & -2.14 & +4.47 & & & & \\
\hline & & d & -2.15 & +4.48 & & & & \\
\hline \multirow[t]{5}{*}{129.5} & 503A-31-1, 5-7 & a & -2.53 & +4.55 & -2.60 & 0.09 & +5.00 & 0.26 \\
\hline & & b & -2.67 & +5.00 & & & & \\
\hline & & c & -2.66 & +5.08 & & & & \\
\hline & & d & -2.48 & +4.73 & & & & \\
\hline & & e & -2.65 & +5.18 & & & & \\
\hline \multirow[t]{3}{*}{139.3} & -503A-33-1, 108-110 & a & -2.98 & +4.78 & -2.89 & 0.17 & +4.78 & 0.17 \\
\hline & & b & -3.00 & +4.61 & & & & \\
\hline & & c & -2.70 & +4.94 & & & & \\
\hline \multirow[t]{2}{*}{164.6} & -503A-39-1, Top A & a & -2.49 & +4.65 & -2.46 & 0.05 & +4.70 & 0.06 \\
\hline & & b & -2.42 & +4.74 & & & & \\
\hline \multirow[t]{2}{*}{164.6} & -503A-39-1, Тор B & a & -3.20 & +4.06 & -2.95 & 0.35 & +4.06 & 0.00 \\
\hline & & b & -2.70 & +4.06 & & & & \\
\hline 227.8 & 503A-53-2, 12-14 & & -1.23 & +3.99 & -1.23 & - & +3.99 & - \\
\hline 11.8 & $503 \mathrm{~B}-4-1,21-23$ & & -1.93 & +4.90 & -1.93 & - & +4.90 & - \\
\hline 19.4 & 503B-5-3, 36-38 & & -1.80 & +4.50 & -1.80 & - & +4.50 & - \\
\hline 31.4 & 503B-8-2, 70-72A & & -0.26 & +1.05 & -0.26 & - & +1.05 & - \\
\hline 31.4 & $503 \mathrm{~B}-8-2,70-72 \mathrm{~B}$ & & -3.05 & +5.33 & -3.05 & - & +5.33 & - \\
\hline \multirow[t]{4}{*}{51.3} & -503B-13-1, 6-8 & a & -2.92 & +5.99 & -2.77 & 0.15 & +5.63 & 0.36 \\
\hline & & b & -2.58 & +5.13 & & & & \\
\hline & & c & -2.86 & +5.72 & & & & \\
\hline & & d & -2.71 & +5.69 & & & & \\
\hline 67.0 & 503B-16-2, 105-107 & & -2.52 & +4.92 & -2.52 & - & +4.92 & - \\
\hline \multirow[t]{2}{*}{80.8} & 503B-19-3, 18-20 & a & -2.81 & +4.46 & -2.81 & 0.00 & +4.49 & 0.04 \\
\hline & & b & -2.81 & +4.51 & & & & \\
\hline
\end{tabular}

Note: Subsamples are listed in order from the outside of each nodule to the inside; $\boldsymbol{*}^{\boldsymbol{*}}$ indicates sample is not in situ.

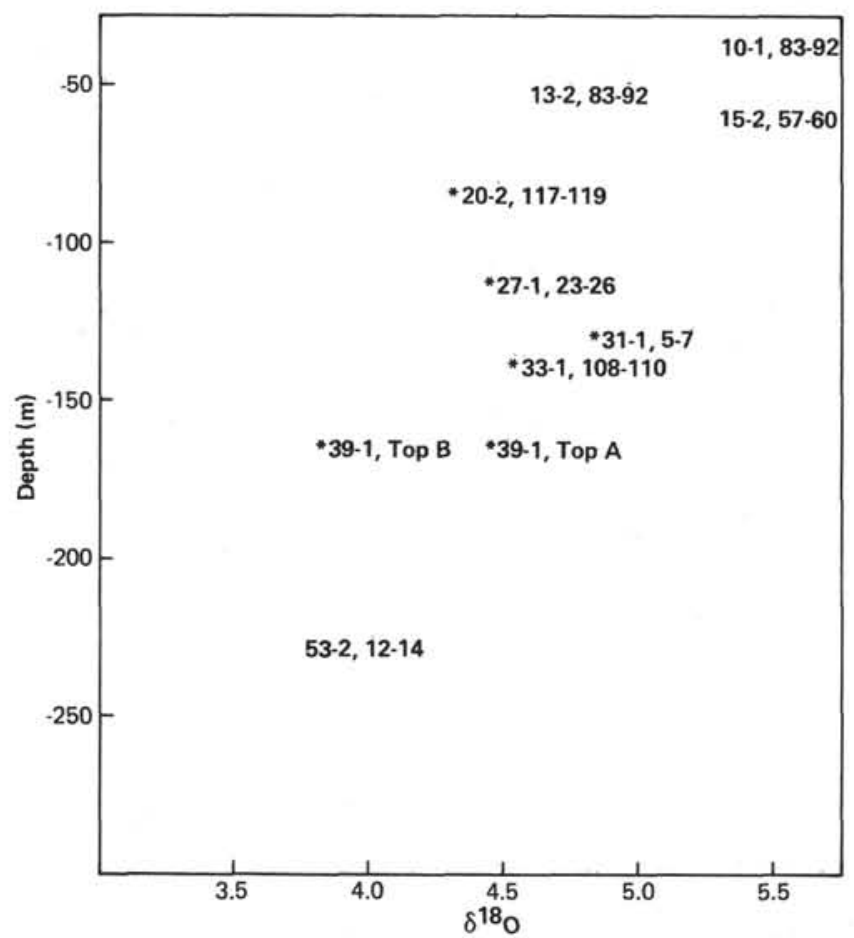

Figure 5. Variation of $\delta^{18} \mathrm{O}$ of carbonate with depth for Hole 503A. $(*$ = sample is not in situ.).

for Hole 503B. The difference results from the sample coverage for the two holes, the latter extending only to 80 meters. Thus it appears that in the upper part of the system there is a more random variation in $\delta^{18} \mathrm{O}$ but

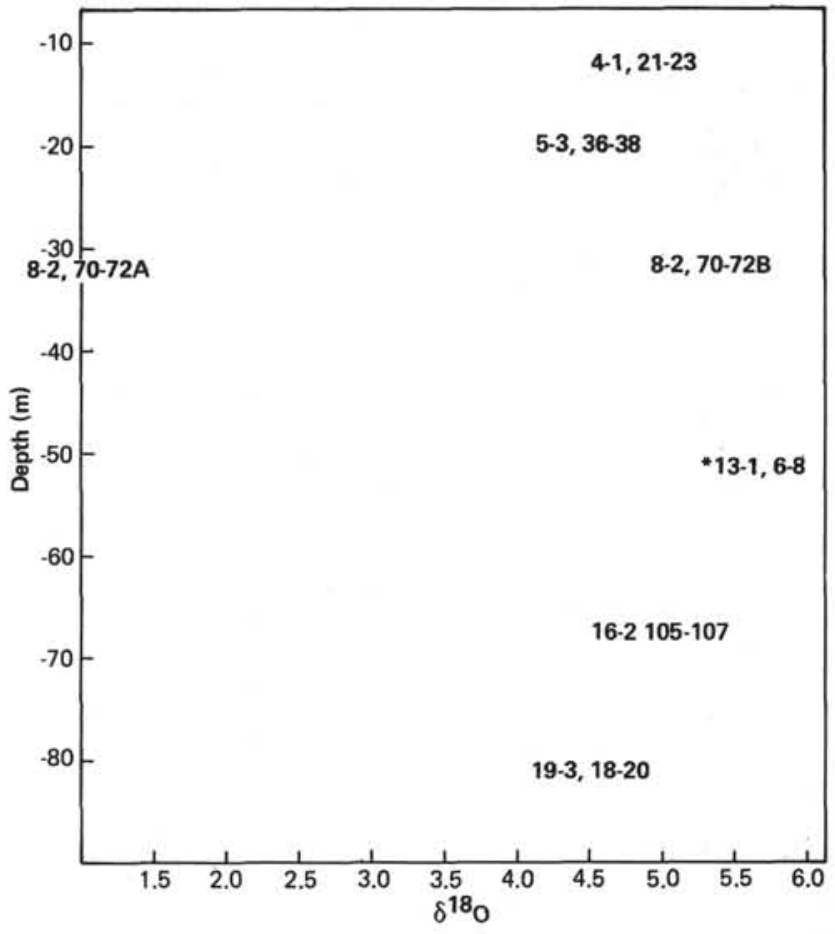

Figure 6. Variation of $\delta^{18} \mathrm{O}$ of carbonate with depth for Hole 503B. $(*=$ sample is not in situ. $)$

below about 100 meters there is a trend to lighter values (data for both holes together are shown in Fig. 7). The exception to this trend is Sample 503B-8-2, 70-72A, which is the soft sediment filling of a burrow and gives values typical of a normal, non-manganoan marine carbonate. The trends themselves may be blurred by the fact that many samples are not in situ. It may be possible to relate the small scale variations in $\delta^{18} \mathrm{O}$ in the upper parts of the holes to variations in seawater $\delta^{18} \mathrm{O}$, similar to those measured by Shackleton and Opdyke (1976).

The exact reason for the relatively more negative $\delta^{18} \mathrm{O}$ of the carbonates from greater depths is not immediately apparent. If we assume that the nodules were formed near the sediment surface, then the isotope composition of the carbonate might have been changed by addition of successive diagenetic carbonates formed at deeper levels and filling residual pore space. Even if subsequent carbonates were not precipitated, the production of bicarbonate by other organic degradation processes would allow ready exchange. In this way, and also in the absence of additional bicarbonate, the poorly crystallized manganoan carbonates could exchange isotopically at higher temperatures and with possibly isotopically more negative pore water. In an attempt to elucidate this problem a more detailed analysis was made of the data from the subsamples within each nodule.

\section{Isotopic Variation within Nodules}

The variations in $\delta^{13} \mathrm{C}$ and $\delta^{18} \mathrm{O}$ for subsamples within five of the nodules are shown in Figure 8. Full sample numbers are not given but the numbers 1 to 5 , respectively, refer to Samples 503A-10-1, 83-92 cm; 503A-27$1,23-26 \mathrm{~cm}$; 503A-31-1, 5-7 cm; 503A-33-1, 108-110 


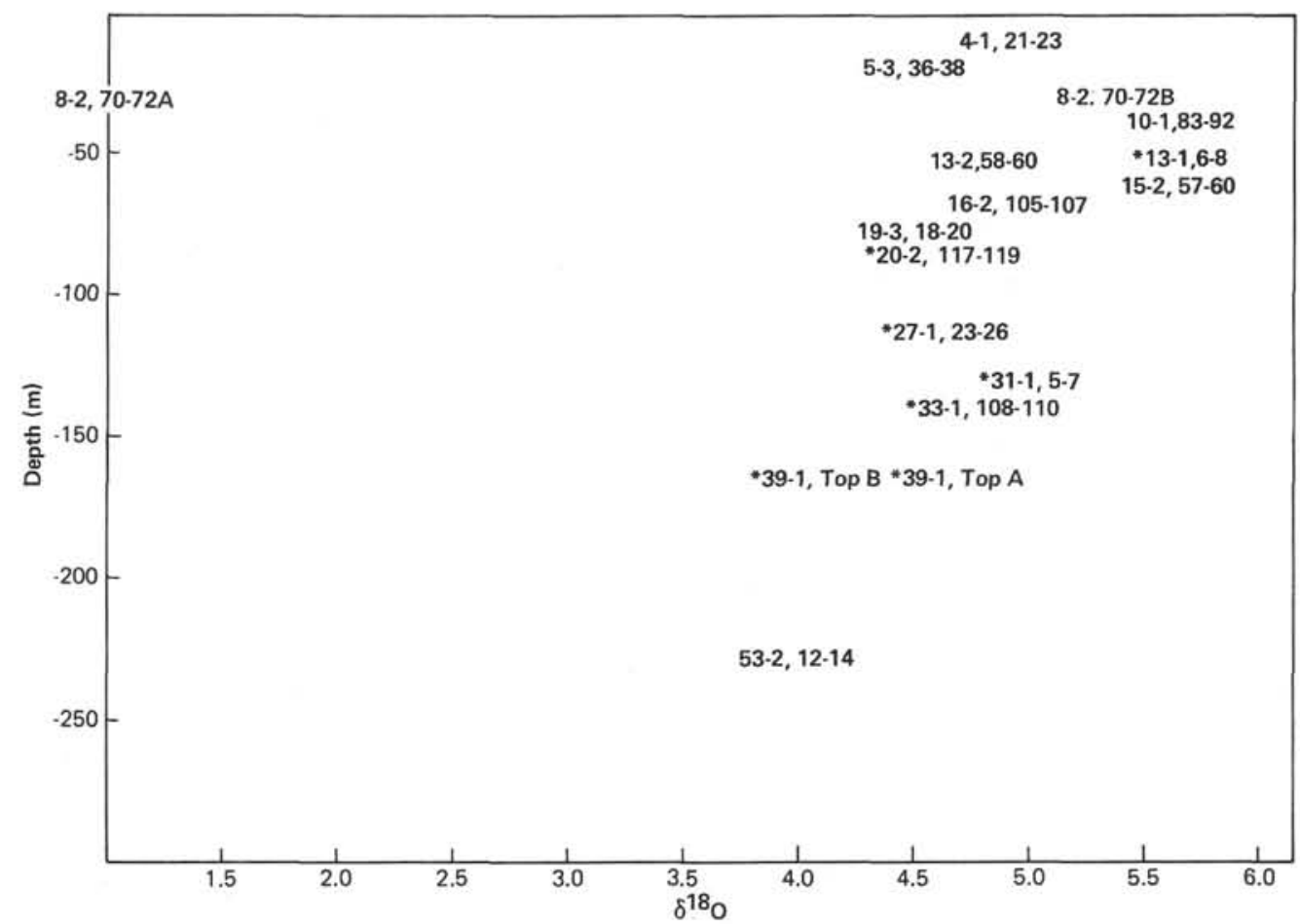

Figure 7. Variation of $\delta^{18} \mathrm{O}$ of carbonates with depth for Holes 503A and 503B $\left({ }^{*}=\right.$ sample is not in situ.)

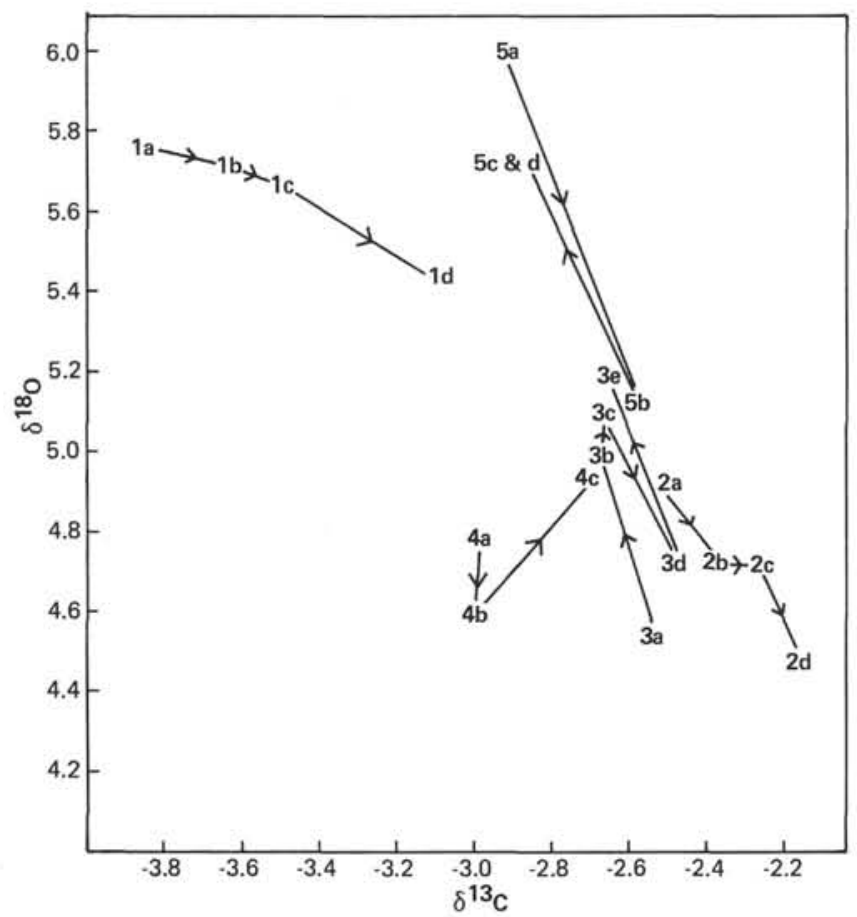

Figure 8. Carbon and oxygen isotope compositions of successive subsamples from outside to within nodules.

$\mathrm{cm}$; 503B-13-1, 6-8 cm. The suffixes "a" to "e" refer to samples taken from the outermost part of the nodule successively toward the center (the burrow itself). For two of the nodules ( 1 and 2 ) there is a clear progression to heavier carbon and lighter oxygen in approaching the center of the nodule. Since the nodules appear to have grown by permeation out from a burrow, this would imply a source of marine carbonate within the burrow mixing with organogenetic carbonate from the pore water outside. The marine bicarbonate could be produced by dissolution of lime mud in pellets. Not all the nodules show this trend, however, and the rest show no clear trend at all. This may reflect the fact that the variations represent subsequent additions of diagenetic carbonate which will be precipitated where there is pore space and where the permeability is greatest. Thus, its individual history of cementation may determine whether the burrow itself allows better access to pore fluids than does the exterior carbonate rim.

\section{CONCLUSIONS}

Our work so far has not allowed us to reach firm conclusions about the mode of genesis of these nodules. Nevertheless, certain alternatives can be presented. Two sources of carbonate might be involved. One could be marine bicarbonate from either the overlying seawater or from pore water (the latter may have acquired its carbonate by dissolution of primary carbonate at depth). The other source of carbonate could be oxidation of organic matter by $\mathrm{MnO}_{2}$, or possibly by any of the successive processes which might occur on burial of the sediment.

In either case the carbonate has precipitated from pore waters very rich in $\mathrm{Mn}^{2+}$. It appears probable that the burrows play an essential part in the process but whether as producers of solutions saturated in bicarbonate by dissolution of pellets or as localized microenvironments is not clear. These questions may be resolved by additional work being done on the samples. 


\section{ACKNOWLEDGMENTS}

We would like to thank David Atkin (IGS) for his help in providing XRD data, Dr. A. C. Bishop, Keeper of Mineralogy, British Museum [Natural History], for making the microprobe facilities available, and Jenny Bevan and Gary Jones (BM [NH]) for their patient help and advice with the microprobe analyses. Gordon Burton (BM [NH]) provided thin slices of the nodules for slides thus helping to preserve them, and Tom Easter (Goldsmiths' College) photographed them. We are particularly grateful to Drs. David Kempe (BM [NH]) and Brian Price (Edinburgh University) for providing rapid and constructive reviews of a draft of the paper. The contributions of MLC and PD are published with the approval of the Director, Institute of Geological Sciences (N.E.R.C.). Finally, AJF thanks his Leg 68 shipboard colleagues for "landing" him with the problem of the nodules.

\section{REFERENCES}

Blatt, H., and Brown, V. M., 1974. Prophylactic separation of heavy minerals. J. Sediment Petrol., 44:260-261.

Coleman, M. L., and Hudson, J. D., 1980. Isotopic composition of bacteriogenic sulphide and some associated barite and carbonates from Jurassic mudstones. Institute of Geological Sciences, Stable Isotope Report No. 46.

Coleman, M. L., and Raiswell, R., 1981. Carbon, oxygen and sulphur isotope variations in concretions from the Upper Lias of N. E. England. Geochim. Cosmochim. Acta, 45:329-340.

Craig, H., 1957. Isotopic standards for carbon and oxygen and correction factors for mass spectrometer analysis of carbon dioxide. Geochim. Cosmochim. Acta, 12:133-149.

Curtis, C. D., 1977. Sedimentary geochemistry: Environments and processes dominated by involvement of an aqueous phase. Phil. Trans. Roy. Soc. London, A286:353-372.

Deines, P., 1970. Mass spectrometer correction factors for the determination of small isotopic variations of carbon and oxygen. Int. J. Mass Spectrom. Ion Phys., 4:283-295.
Froelich, P. N., Klinkhammer, G. P., Bender, M. L., Luedtke, N. A., Heath, G. R., Cullen, D., Dauphin, P., Hammond, D., Hartman, B., and Maynard, V., 1979. Early oxidation of organic matter in pelagic sediments of the eastern equatorial Atlantic: suboxic diagenesis. Geochim. Cosmochim. Acta, 43:1075-1090.

Hays, J. D., et al., 1972. Init. Repts. DSDP, 9: Washington (U.S. Govt. Printing Office).

Hudson, J. D., 1975. Stable isotopes and limestone lithification. J. Geol. Soc. Lond., 133:637-660.

Lawrence, J. R., Gieskes, J. M., and Broecker, W. S., 1975. Oxygen isotope and cation composition of DSDP pore waters and the alteration of Layer II basalts. Earth Planet. Sci. Lett., 27:1-10.

Lynn, D. C., and Bonatti, E., 1965. Mobility of manganese in diagenesis of deep-sea sediments. Mar. Geol., 3:457-474.

McCrea, J. M., 1953. The isotopic chemistry of carbonates and a palaeotemperature scale. J. Chem. Phys., 18:849-857.

O'Neil, J. R., Clayton, R. N., and Mayeda, T. K., 1969. Oxygen isotope fractionation in divalent metal carbonates. J. Chem. Phys., $51: 5547-5558$.

Shackleton, N. J., and Opdyke, N. D., 1976. Oxygen isotope and paleomagnetic stratigraphy of Pacific core V28-239 late Pliocene to latest Pleistocene. In Cline, R. M., and Hays, J. D. (Eds.), Quaternary Paleoceanography and Paleoclimatology: Geol. Soc. Am. Mem., 145:449-464.

Sharma, T., and Clayton, R. N., 1965. Measurement of ${ }^{18} \mathrm{O} /{ }^{16} \mathrm{O}$ ratios of total oxygen of carbonates. Geochim. Cosmochim. Acta, 29: 1347-1353.

Weber, J. M., Deines, P., Weber, P. H., and Baker, P. A., 1976. Depth related changes in the ${ }^{13} \mathrm{C} /{ }^{12} \mathrm{C}$ ratio of skeletal carbonate deposited by the Caribbean reef-frame building coral Montastrea annularis: further implications of a model for stable isotope fractionation by scleractinian corals. Geochim. Cosmochim. Acta, 40:31-39. 